\title{
Lessons from a Phenotyping Center Revealed by the Genome-Guided Mapping of Powdery Mildew Resistance Loci
}

\author{
Lance Cadle-Davidson, David Gadoury, Jonathan Fresnedo-Ramírez, Shanshan Yang, Paola Barba, Qi Sun, \\ Elizabeth M. Demmings, Robert Seem, Michelle Schaub, Anna Nowogrodzki, Hema Kasinathan, \\ Craig Ledbetter, and Bruce I. Reisch
}

First and ninth authors: U.S. Department of Agriculture-Agricultural Research Service (USDA-ARS), Grape Genetics Research Unit, Geneva, NY 14456; second, fourth, fifth, seventh, eighth, tenth, eleventh, and thirteenth authors: School of Integrative Plant Science, Cornell University, New York State Agricultural Experiment Station, Geneva 14456; third and sixth authors: Bioinformatics Facility, Cornell University, Ithaca, NY 14853; and twelfth author: USDA-ARS, Crop Disease, Pests and Genetics Unit, Parlier, CA 93648. Current address of fifth author: Instituto de Investigaciones Agropecuarias INIA, La Platina Research Station, Avenida Santa Rosa 11610, La Pintana, 8831314, Santiago, Chile.

Accepted for publication 21 April 2016.

\begin{abstract}
Cadle-Davidson, L., Gadoury, D., Fresnedo-Ramírez, J., Yang, S., Barba, P., Sun, Q., Demmings, E. M., Seem, R., Schaub, M., Nowogrodzki, A., Kasinathan, H., Ledbetter, C., and Reisch, B. I. 2016. Lessons from a phenotyping center revealed by the genome-guided mapping of powdery mildew resistance loci. Phytopathology 106:1159-1169.

The genomics era brought unprecedented opportunities for genetic analysis of host resistance, but it came with the challenge that accurate and reproducible phenotypes are needed so that genomic results appropriately reflect biology. Phenotyping host resistance by natural infection in the field can produce variable results due to the uncontrolled environment, uneven distribution and genetics of the pathogen, and developmentally regulated resistance among other factors. To address these challenges, we developed highly controlled, standardized methodologies for phenotyping powdery mildew resistance in the context of a phenotyping center, receiving

samples of up to 140 grapevine progeny per $F_{1}$ family. We applied these methodologies to $\mathrm{F}_{1}$ families segregating for REN1- or REN2-mediated resistance and validated that some but not all bioassays identified the REN1 or REN2 locus. A point-intercept method (hyphal transects) to quantify colony density objectively at 8 or 9 days postinoculation proved to be the phenotypic response most reproducibly predicted by these resistance loci. Quantitative trait locus (QTL) mapping with genotyping-by-sequencing maps defined the REN1 and REN2 loci at relatively high resolution. In the reference PN40024 genome under each QTL, nucleotide-binding site-leucine-rich repeat candidate resistance genes were identified - one gene for REN1 and two genes for REN2. The methods described here for centralized resistance phenotyping and highresolution genetic mapping can inform strategies for breeding resistance to powdery mildews and other pathogens on diverse, highly heterozygous hosts.
\end{abstract}

Genomic tools have enhanced our knowledge of the biology and genetics of host resistance (Dangl et al. 2013; Guttman et al. 2014). The rate at which our knowledge has increased has accelerated as these tools have been improved and increasingly applied and refined. While proteomic and transcriptomic analyses of expression have revealed dynamic interactions between hosts and pathogens, genomes and genome-wide markers have revealed the genetic blueprints that determine those interactions. Among the most relevant genomic features that determine the outcome of host-pathogen interactions are genetic loci at which nucleotide-binding site-leucine-rich repeats (NLR, or NBS-LRR) resistance genes are clustered; these are a cornerstone of disease resistance breeding in most crops. The publication of the grapevine genome in 2007 revealed over 500 NLR genes, the majority (83\%) of which were present in clusters (Jaillon et al. 2007). Given that most resistance loci with qualitative, dominant inheritance co-localize with NLR clusters, breeders and geneticists developed strategies for targeted mapping of resistance phenotypes to NLR clusters (Riaz et al.

Corresponding author: Lance Cadle-Davidson;

E-mail address: Lance.CadleDavidson@ars.usda.gov

*The $\boldsymbol{e}$-Xtra logo stands for "electronic extra" and indicates that one supplementary figure is published online.

http://dx.doi.org/10.1094/PHYTO-02-16-0080-FI

This article is in the public domain and not copyrightable. It may be freely reprinted with customary crediting of the source. The American Phytopathological Society, 2016.
2011). This remains a logical first step in the development of resistant cultivars for grapevine and other crops where host resistance is highly desired by producers not yet widely deployed in commercial production. However, the known weakness of targeting NLR loci is race specificity of resistance, which can be a powerful driver of selection for pathogen races able to overcome NLR-mediated resistance (Barba et al. 2015; Feechan et al. 2015; Ramming et al. 2012). While the genome offered opportunities for targeting NLRs, genomic tools like genotyping-bysequencing (GBS) markers also offered opportunities for rapid and unbiased genetic discovery genome-wide (Barba et al. 2014; Elshire et al. 2011; Hyma et al. 2015). Having overcome barriers to obtaining genome-wide data, the challenge now is how to obtain robust and relevant quantitative phenotypes for proper application of genomic tools.

Relying upon naturally occurring infection to phenotype host resistance to powdery mildew can produce variable results due to the uncontrolled environment, uneven spatiotemporal distribution of inoculum dose, diverse and changing pathogen genotypes, and developmentally regulated resistance, to name only the principal factors that have been identified as influential in prior studies. This is especially problematic in breeding and genetic analysis of large perennial plants, such as grapevine, where it can be impractical to maintain large replicated plantings. In particular, genetic mapping of resistance requires precise and reproducible results to detect marker-trait linkages that can be used for marker-assisted breeding and stacking of resistance genes.

In grapevine, a number of qualitatively inherited loci have been characterized as conferring resistance to powdery mildew, caused 
by Erysiphe necator. REN2 on chromosome 14 was the first powdery mildew resistance locus mapped in grapevine (Dalbò et al. 2001), as a locus introgressed from $V$. cinerea B9. REN2 confers a programmed cell death-mediated resistance of moderate strength that is race specific. Preliminary evidence suggests REN2 may enhance the durability of $V$. rotundifolia-derived resistance genes, such as RUN1 (Feechan et al. 2013, 2015). REN1 on chromosome 13 represents a Central Asian source of resistance from $V$. vinifera (Hoffmann et al. 2008), the cultivated grapevine that by all other observations is universally susceptible to powdery mildew. While race specificity of REN1 is uncharacterized, it co-localizes to a cluster of CC-NBS-LRR genes and confers a slow posthaustorial resistance that results in sparse colonies with minimal sporulation (Hoffmann et al. 2008).

To address the challenges in phenotyping powdery mildew resistance for genetic and genomic studies, we developed a powdery mildew phenotyping center, attempting to control variables listed above, including environment, inoculum dose, pathogen genotype, and leaf age. To validate our approaches, we used grape families known to segregate for REN1 and/or REN2, applying GBS for the genome-wide mapping of resistance as quantitative trait loci (QTL), in comparison with conventional phenotyping strategies.

\section{MATERIALS AND METHODS}

Vine establishment and maintenance. In 2011, the cross C81-227 × Y315-43-04 (11-3527 family) was made with the purpose of combining REN2 (C81-227) and REN1 (Y315-43-04) sources of powdery mildew resistance. Harvested seed were stratified, germinated, and transplanted to Anderson bands (\#2007, Anderson Pots, Portland, OR) for a first year of growth in a shadehouse. A total of 362 seedlings were germinated and genotyped, from which 205 arbitrarily selected seedlings were field transplanted in May 2013 to their permanent location in Field 12 of the San Joaquin Valley Agricultural Sciences Center research vineyard in Parlier, CA. Included with this planting were 1-year-old rooted clones of 'Ruby Seedless' and 'Thompson Seedless', planted alternately every 15 th vine to provide powdery mildew inoculum and to serve as susceptible controls. Plant spacing was $0.91 \mathrm{~m}$ within the row, and $3.66 \mathrm{~m}$ between rows. Vines received water through drip irrigation installed at the soil surface. Vines were trained intensively to achieve fruiting as soon as possible, with numerous pruning passes through the family during the first year of growth to establish a vegetative head and produce vigorous cane growth. Vines were cane-pruned during dormancy, leaving two to four canes as fruiting wood for the next season. Fungicides were not applied in the field where 11-3527 vines were planted. Weed control was accomplished in-row with a late dormant season contact (paraquat dichloride) and pre-emergent (oryzalin) tank mix, whereas between row weeds were mowed as necessary. Cryolite (trisodium hexafluoroaluminate) and Admire (imidacloprid) were applied in the early season for control of thrips and leafhoppers, respectively, and Movento (spirotetramat) was applied for mealybug control in mid-June. Grapevines with REN1 resistance had been grown in this breeding vineyard since 2010 .

In 2009, the cross 'Horizon' $\times$ V. cinerea B9 (NY09.0805 family) was made to characterize REN2 powdery mildew resistance and other traits from $V$. cinerea B9. Seeds were stratified and germinated in a greenhouse in March 2010, and seedlings were then grown in an irrigated nursery for one season. A total of 164 seedlings were transplanted to a permanent vineyard in 2011 in Geneva, New York. Included with this planting were 1-year-old rooted clones of 'Chardonnay' clone 95, planted every 15 th vine, to provide powdery mildew inoculum and to serve as a susceptible control. In addition, there were two control plots in separate rows each consisting of single vines of $V$. cinerea $\mathrm{B} 9$, 'Horizon', 'Chardonnay' clone 95, NY88.0514.04 (powdery mildew resistant control), and 'Chancellor' (powdery mildew susceptible control). Plant spacing was $1.2 \mathrm{~m}$ within the row, and $2.74 \mathrm{~m}$ between rows. Vines received no supplemental irrigation. Vines were trained intensively to achieve fruiting as soon as possible, with multiple passes through the family during the first 2 years to establish growth on the top trellis wire. Vines were cane-pruned during dormancy, leaving two to four canes (20 to 40 buds) as fruiting wood for the next season. From 2012, fungicides that do not provide powdery mildew control in vineyard conditions, such as Captan 80 WPG, ProPhyt, Revus 2 SC, and Reason 500 SC, were applied after bloom to control phomopsis and downy mildew so that otherwise healthy leaf tissue could be rated for powdery mildew resistance. Before bloom, Quintec 2SC was added on two occasions in order to protect vines from conidial and ascosporic inoculum of E. necator resulting from disease development the previous season. No powdery mildew control was applied after bloom (first or second week of June). Weed control was accomplished inrow with both pre-emergent and contact herbicides, whereas between row grass and weeds were mowed as necessary. Grapevines with REN2 resistance had been grown in a nearby vineyard since 1988 .

Vegetative cuttings of several genotypes were propagated to serve as controls. Potted vines were maintained in the U.S. Department of Agriculture (USDA)-Agricultural Research Service greenhouse in Geneva, NY, to harvest optimum quality leaves for uniform disease evaluations. Three genotypes were used as controls on each inoculation date: (i) V. vinifera 'Chardonnay' or 'Cabernet Sauvignon' served as a highly susceptible control; (ii) the breeding line JB81107-11 carrying the $R U N 2.1$ locus on chromosome 18 served as a moderately resistant control; and (iii) $V$. cinerea B9 carrying the REN2 locus on chromosome 14 served as a moderately resistant control.

Vineyard rating following natural infection. Individual field planted vines of 11-3527 were evaluated for powdery mildew susceptibility during the 2014 and 2015 (second and third leaf, respectively) growing seasons. Disease severity was evaluated subjectively by one person in both growing seasons. Vegetative budbreak for grapes generally begins in early March in the central San Joaquin Valley (Parlier, CA), with the bloom period following from mid-April through mid-May. Since disease severity was rated independently on the leaf, stem, rachis and berry tissues of each growing vine, evaluations were most appropriate during June, when developing fruit clusters were both available and easily scored for presence and abundance of sporulating powdery mildew strikes. Powdery mildew susceptible 'Ruby Seedless' and 'Thompson Seedless' vines interplanted with the 11-3527 family were also subjectively evaluated for powdery mildew presence on leaves, stems, rachis and berries using the following scale: $1=$ no observed infections; $2=$ very few small colonies; $3=<50 \%$ of area affected; and $4=>50 \%$ of area affected, as previously described (Ramming et al. 2012). All vines were evaluated for disease severity in mid-June 2014, mid-June 2015, and mid-October 2015.

Individual field-planted vines of NY09.0805 were evaluated for powdery mildew severity on 25 August 2011, 17 and 25 September 2012, 17 September 2013, and 27 August and 3 September 2014. Disease severity was evaluated subjectively from the west side of the vine by the same person each time as previously described in Barba et al. (2015) using the IPGRI scale established by the Organization Internationale de la Vigne et du Vin and described by the International Union for the Protection of New Varieties of Plants (IPGRI, UPOV, and OIV 1997): 1 = tiny spots or no symptoms, neither visible sporulation nor mycelium; $3=$ limited patches $<2 \mathrm{~cm}$ in diameter, limited sporulation and mycelium; $5=$ medium (patches usually limited with a diameter of 2 to $5 \mathrm{~cm}$ ); 7 = vast patches, some limited, strong sporulation and abundant mycelium; and $9=$ very vast unlimited patches or totally attacked leaf blades, strong sporulation and abundant mycelium.

Pathogen isolate maintenance and inoculation. E. necator isolate NY1-137 was collected from a Vitis interspecific hybrid grapevine with the $R U N 1$ resistance locus in New York, and isolate RoACS was collected from V. vinifera 'Cabernet Sauvignon' in North Carolina (Barba et al. 2015; Feechan et al. 2015; Frenkel 
et al. 2010). These single-conidial isolates were prepared and maintained on surface-sterilized detached leaves of $V$. vinifera 'Chardonnay', as described previously (Barba et al. 2015; Feechan et al. 2015). For inoculation in controlled experiments, conidial suspensions were prepared by shaking about seven leaves with visible 7 - to 10-day-old powdery mildew colonies in $20 \mathrm{ml}$ of $0.001 \%$ Tween 20 in sterile water. The inoculum concentration was adjusted to $10^{5}$ conidia $\mathrm{ml}^{-1}$. Inoculation was performed using a hand-held atomizer (Preval, Coal City, IL) as described by Gadoury et al. (2003).

Leaf sampling and processing for controlled inoculation. To phenotype resistance of the vineyard-grown parents and progeny in controlled experiments, one leaf from each of four replicate shoots was sampled at the third node, typically being translucent and about half the width of a fully expanded leaf. Standardizing leaf age is essential due to foliar ontogenic resistance in this pathosystem (Gadoury et al. 2012a; Gee et al. 2008). Prior to processing a full experiment for a given family, a preliminary experiment was conducted to identify which isolate and leaf age (third node here) provided the greatest separation between parent phenotypes, assuming this would maximize the distribution of phenotypes in the progeny. The isolate used and specific details of each experiment are presented in Table 1. To promote uniform sampling and handling, sampling protocols and materials were provided to each breeding program in advance (Supplementary Fig. S1). In addition to the vineyard-sampled leaves, leaves from the third node were also sampled from several greenhouse-grown potted vines that served as susceptible or resistant controls. Immediately upon sampling, leaves were placed in a plastic box at approximately $4^{\circ} \mathrm{C}$ until processing the following day and then surface-sterilized as previously described (Cadle-Davidson et al. 2011). After sterilization, excess moisture was removed by placing the leaves on a sterile paper towel inside a sterile laminar flow hood, and a $10-\mathrm{mm}-$ diameter leaf disc (using cork borer no. 7) was made on each side of the leaf midrib to obtain two subsampled discs per leaf. The leaf discs were plated immediately on $1 \%$ water agar, contained in glass dishes $(23 \times 33 \mathrm{~cm}$; Pyrex 233-R, Corning Glass, Corning, NY) prelabeled to track up to 260 discs. The dishes were covered with plastic wrap and maintained at $23^{\circ} \mathrm{C}$ in a 12 -h photoperiod until inoculation using a handheld paint sprayer (Preval, Coal City, IL) at 11 a.m. the next day. The leaves were collected from four different shoots (block or replicate), and two discs per leaf were subsamples in a balanced, lattice design. Each subsample (block) was contained in one of eight glass dishes.

Evaluation after controlled inoculation. Inoculated samples were maintained at $23^{\circ} \mathrm{C}$ in a 12 -h photoperiod until processing. For microscopic evaluation, samples were cleared in 3:1, vol/vol, ethanol/acetic acid until the tissue was completely bleached, then transferred to $50 \%$ ethanol for storage at $23^{\circ} \mathrm{C}$. The discs were stained with Coomassie Brilliant Blue R-250 (Bio-Rad Laboratories, Richmond, CA) and mounted for data collection using a compound microscope, as described previously (Ramming et al. 2012). In this pathosystem, primary hyphae germinate from conidia to form primary appressoria, and will do so irrespective of the nature or physical properties of the surface (Gadoury et al. 2012a). After penetration and establishment of haustoria, one or more secondary hyphae are formed indicating successful penetration. Penetration success rate was quantified at 2 days postinoculation (dpi) as the percentage of germinated conidia with at least one secondary hypha. Colony success rate was quantified at $2 \mathrm{dpi}$ as the percentage of penetrating conidia with multiple secondary hyphae and/or branching hyphae. Overall success rate was quantified at $2 \mathrm{dpi}$ as the percentage of germinated conidia with multiple secondary hyphae and/or branching hyphae.

For samples with longer incubation times ( 8 to $9 \mathrm{dpi}$ ), several responses were evaluated: (i) preclearing visual rating; (ii) preclearing incidence of conidiation; (iii) length of longest hypha emerging from a conidium; and (iv) number of hyphae intercepting a transect through a microscopic field of view. For (i) visual ratings, a 4-point categorical scale was developed for rapid assessment immediately prior to leaf clearing: $1=$ no visible powdery mildew; $2=$ visible powdery mildew but less than $50 \%$ coverage; $3=$ more than $50 \%$ but less than $100 \%$ coverage; and $4=100 \%$ coverage. In addition, for (ii) the presence or absence of conidiation was recorded. Discs were then cleared for Coomassie staining as described above for data collection using a compound microscope. Previous studies indicated hyphal length could be used to distinguish resistant from susceptible progeny when differences in penetration and colony success rate were not discriminatory (Ramming et al. 2012). For (iii) measurement of hyphal length, up to eight arbitrarily selected fields of view were observed, and the length of the longest hypha in each field of view was recorded as a percentage of a $\times 200$ field of view. For hyphal transects, the number of interceptions of individual hyphae crossing one of two axial transects (vertical and horizontal) were counted within a $\times 200$ field of view. The cube root transformation of hyphal transects described under QTL mapping methods is annotated in the results as TransectT.

Correlations ( $r$ value) across traits and experiments were estimated by the REML method in JMP Pro version 12.0.1 (SAS Institute, Cary, NC). For correlation analysis, rating scales were converted from categorical to continuous variables as follows, based on the estimated midpoint of the described range. For (i) visual ratings, $1=2.5 \% ; 2=27.5 \% ; 3=72.5 \%$; and $4=97.5 \%$. For $11-3527$ field ratings, $1=0.5 \% ; 2=4.5 \% ; 3=30 \%$; and $4=75 \%$. For NY09.0805 field ratings, $1=11.1 \%$, and each incremental rating step increased by $11.1 \%$, from $2=22.2 \%$ up to $9=100 \%$.

Genetic map construction. Molecular marker-based genetic maps for the parents of NY09.0805 family were previously published (Hyma et al. 2015). For 11-3527, DNA was isolated using a modified DNeasy 96-well DNA extraction kit (Qiagen, Valencia, CA) for 384plex GBS, as described previously (Hyma et al. 2015; Yang et al. 2016a). For single nucleotide polymorphism (SNP) calling, the raw

TABLE 1. Details of each controlled inoculation experiment

\begin{tabular}{|c|c|c|c|c|c|}
\hline Family & $\begin{array}{l}\text { Sampling date } \\
\text { (MMDDYY) }\end{array}$ & Conidia $\mathrm{ml}^{-1}$ & $\begin{array}{c}\text { Number of } \\
\text { progeny }\end{array}$ & $\mathrm{dpi}^{\mathrm{a}}$ & Data types collected \\
\hline \multicolumn{6}{|c|}{$\begin{array}{l}\text { C81-227 × Y315-43-04 (11-3527 family), } \\
\text { inoculated with isolate RoACS }\end{array}$} \\
\hline & 091712 & $1.1 \times 10^{5}$ & 161 & 9 & Longest hypha, hyphal transects, sporulation \\
\hline & 072213 & $1.2 \times 10^{4}$ & 165 & 9 & Hyphal transects, preclearing visual rating, sporulation \\
\hline & 052714 & $7.6 \times 10^{4}$ & 138 & 8 & Hyphal transects, preclearing visual rating \\
\hline & 060214 & $5.1 \times 10^{4}$ & 137 & 8 & Hyphal transects, preclearing visual rating, sporulation \\
\hline \multicolumn{6}{|c|}{$\begin{array}{l}\text { 'Horizon' } \times \text { Vitis cinerea B9 (NY09.0805 } \\
\text { family), inoculated with isolate NY1-137 }\end{array}$} \\
\hline & 062512 & $1.7 \times 10^{5}$ & 91 & 2 & Penetration, colony, and overall success rates \\
\hline & 062314 & $6.7 \times 10^{4}$ & 136 & 8 & Hyphal transects, sporulation \\
\hline & 063014 & $4.2 \times 10^{4}$ & 138 & 8 & Hyphal transects, sporulation \\
\hline
\end{tabular}

a Days postinoculation. 
sequence data for the two parents and $362 \mathrm{~F}_{1}$ progeny were processed through the TASSEL 3.0 GBS pipeline (Glaubitz et al. 2014) using the 12X.2 V. vinifera 'PN40024' reference genome (Jaillon et al. 2007) for alignment and the Burrows-Wheeler aligner mem (BWAMEM) algorithm (Li and Durbin 2009) with default parameters. The output consisted of variant call format (VCF) file version 4.1 (Danecek et al. 2011) including SNPs present in at least $40 \%$ of the progeny and with a minor allele frequency of $\geq 0.1$.

Subsequently, the VCF was filtered using vcftools ver. 1.12a (Danecek et al. 2011), and using the routine-relatedness, individuals that may have resulted from either self-fertilization of C81-227 or pollen contamination were removed. SNPs were identified for 284 confirmed progeny with high quality GBS data, using TASSEL 3.0, and a custom filtering process was applied to keep sites with a minimum read depth of 6 and $85 \%$ completeness by site across progeny and by progeny across sites. Results were output as a TASSEL hapmap file. Finally, using a custom perl script, pseudotestcross markers (from marker genotypes in the parents of type: $A B$ $\times \mathrm{AA}$ or $\mathrm{AB} \times \mathrm{BB}$, segregating 1:1) and intercross markers (from heterozygous marker genotypes in the parents, and segregating 1:2: 1 , codominant) were identified by a $\chi^{2}$ goodness-of-fit test at $\alpha \leq$ 0.01 , were validated with progenitor genotypes, and were output in the format to be imported in JoinMap 4.1 (Kyazma B. V., Wageningen, Netherlands), as previously described (Yang et al. 2016a).

In JoinMap 4.1 Build: 31jul13.4feb11, cross-pollination (CP) cross type was used to estimate linkages. Prior to grouping and ordering, loci duplicating genetic information or with highly significant $(P \leq 0.00001)$ deviation from Mendelian expectations were discarded. For grouping, a linkage-independence LOD of $\geq 45$ was used. Ungrouped markers were assigned to linkage groups using the routine Assign Ungroup Loci to SCL Groups, considering a minimum LOD score of 35 . For ordering and genetic location determination, the multipoint maximum likelihood mapping algorithm implemented was applied (Van Ooijen 2011), in addition to three rounds of map optimization. To keep the most reliable markers and their locations while limiting distance inflation, a threshold of $2.5 \mathrm{cM}$ for the nearest neighbor stress (N.N. stress) was considered. This is an empirical threshold determined through the linkage mapping of 16 full-sib families analyzed in the USDANIFA Specialty Crop Research Initiative VitisGen project (www. vitisgen.org).

QTL mapping. QTL analysis was performed on each experiment (one trait evaluated in one environment) using the standard composite interval mapping procedure (EM algorithm) with a normal model for hyphal transects and a nonparametric model for field ratings in the package R/qtl (Broman et al. 2003) version 1.38.4 for $\mathrm{R}$ ver. 3.1.2 (R Core Team 2014) using 4-way as the cross type and importing geno, pheno, and map files in MapQTL format. One thousand permutations at $\alpha=0.05$ were executed to calculate the LOD thresholds. Missing genotypes were simulated given observed marker data by the hidden Markov model (sim.geno function in R/qtl). Reports were generated for maximum LOD score, 1.5 LOD interval in centimorgans and physical location in the reference genome, and the percentage of variation explained $\left(R^{2}\right)$.

For 2012 hyphal transects, the data showed significant $(\alpha=0.05)$ heteroscedasticity according to Levene's test and linear model diagnostics, which violates one of the assumptions of QTL mapping. Therefore, a transformation was estimated based on Box-Cox (power) transformations (Sakia 1992), using the package AID version 1.5 for $\mathrm{R}$. The approximated value for power transformation was 0.33 , which is practically a cube root transformation $\sqrt[3]{a}$. This transformation (TransectT) was applied for subsequent experiments.

For QTL mapping of the number of hyphal transects across four experiments, an approach based on linear mixed models for QTL estimation in multiple environments was pursued using the routines VGESELECT, QMTQTLSCAN, QMTESTIMATE, and QMTBACKSELECT (Boer et al. 2014) integrated in the statistical package GenStat for Windows 17th Edition (VSN International, Hemel,
Hempstead, UK). First, only individuals having phenotypic data for all four experiments evaluating hyphal transects were selected. Cofactors were placed each $1.51 \mathrm{cM}$ along the genome, resulting in placement of 1474 cofactors along the genetic map. A QTL model was applied including the estimation of nonadditive effects:

$y_{i j}=\mu+E_{j}+\sum_{f \in F}\left[\left(x_{i f}^{a d d} c_{j f}^{a d d}+x_{i f}^{n a d} c_{j f}^{n a d}\right)+\left(x_{i}^{a d d} a_{j}^{a d d}+x_{i}^{n a d} a_{j}^{n a d}\right)\right]+G E_{i j}$

where $y_{i j}$ is the trait value for genotype $i$ in the environment $j, E_{j}$ is the environment main effect, $F$ is the set of cofactors, $x_{i f}$ add and $x_{i}$ add are the additive genetic predictors of genotype $i$ at the cofactor positions and at the tested position, respectively. The associated effects are denoted by $c_{j f}$ add and $\alpha_{j}$ add for cofactors and tested positions, respectively. $x_{i f}^{\text {nad }}$ and $x_{i}^{\text {nad }}$ are nonadditive genetic predictors of genotype $i$ at the cofactor positions and at the tested position, respectively, with associated effects $c_{j f}$ nad and $\alpha_{j}$ nad. $G E_{i j}$ refers to the residual error of the environment $j$ for genotype $i$. The fit of the unstructured model was iteratively performed through restricted maximum likelihood (REML), using 1,000 iterations. The QTL threshold was set at a significance level of 0.05 using the $\mathrm{Li}$ and $\mathrm{Ji}$ (2005) method with minimum cofactor proximity of $50 \mathrm{cM}$ and minimum separation of selected QTL of $30 \mathrm{cM}$. The $-\log$ $(P$ value) threshold for the significance of the QTL was set at 3.67.

Subsequently, for the interval mapping and estimation of QTL effects, the model was simplified to

$$
y_{i j}=\mu+E_{j}+\sum_{l \in L}\left[\left(x_{i l}^{a d d} a_{j l}^{a d d}+x_{i l}^{n a d} a_{j l}^{n a d}\right)\right]+G E_{i j}
$$

Here, $l \in L$ refers to loci $(l)$ belonging to a set of given QTL $(L)$, with other terms defined above. $G E_{i j}$ is the residual unexplained genetic and environmental variation, which is assumed to be distributed following a multi-normal probabilistic distribution with mean vector 0 , and a variance covariance matrix $\Sigma$. The variancecovariance matrix $\Sigma$ was modeled by the option VGESELECT, which selects the most parsimonious $\Sigma$ to model the genetic correlations between environments. The variance-covariance models compared were: identity, compound symmetry, heteroscedastic diagonal, heterogeneous compound symmetry, heterogeneity outside, first order factor-analytic model and unstructured. The most adequate parsimonious model for $\Sigma$ in this analysis was defined by the AIC and BIC criteria.

The methods to fit these models follow the ideas of Malosetti et al. (2004, 2007) and Boer et al. (2007). Both mixed models consider the genotypes as random terms, while the genetic predictors are fixed effects. The genetic predictors can be considered as genotypic covariates informing the genotypic composition of a genotype at a specific chromosome locus (Lynch and Walsh 1998).

Genome gazing for $\mathbf{R}$-gene candidates. To identify R-gene candidates underlying REN1 and REN2 QTL, previously published NLR sequences (Yang et al. 2008) were used to perform BLASTlike alignment tool (BLAT) queries in the region of the PN40024 version $12 \mathrm{X}$ genome defined by the 1.8-LOD support intervals in this study (http://www.genoscope.cns.fr/blat-server/cgi-bin/vitis/ webBlat). BLAT output was filtered to include only those matches with length values of $40 \mathrm{bp}$ or more and $100 \%$ identity. The query sequences resulting in matches within the 1.8-LOD support intervals were then used to query local alignments through TBLASTN 2.2.26+ queries of the PN40024 version 12X genome at Phytozome 11 (https://phytozome.jgi.doe.gov/pz/portal.html), to return functional annotations.

\section{RESULTS}

Vineyard rating following natural infection. Following natural infection in a breeding vineyard, each family segregated for resistance. In the 11-3527 family segregating for REN1 and 
REN2, a majority (77.4\%) of the progeny were rated 1 (no observed infections) in June 2014 (Fig. 1A), as would be expected in a pseudo-testcross for two independent, qualitative dominant loci. This number declined to $57.5 \%$ by October 2015 , and across three ratings, infections were never observed for 100 of the 196 vines (51.0\%), as would be expected in a pseudo-testcross for a single qualitative dominant locus. For the NY09.0805 family segregating for $R E N 2$, the distribution of ratings was continuous with few individuals $(1.6 \%)$ in the two most resistant classes (i.e., less than $3=$ limited patches $<2 \mathrm{~cm}$ in diameter) (Fig. 1B). Most progeny $(52.5 \%)$ were rated moderate (4 to 6), and on some rating dates (e.g., 9/17/13), the distribution shifted toward a greater number of susceptible progeny (Fig. 1B).

Testing different data types after controlled inoculation. In each experiment involving controlled inoculation, the parents and control individuals known to be susceptible ('Chardonnay' or 'Cabernet Sauvignon') or moderately resistant (V. cinerea B9 and JB81-107-11) were included to evaluate each resistance observation approach. To account for the diverse rating scales used here, susceptibility relative to the susceptible control is presented (Fig. $1 \mathrm{C}$ and D). At 2 dpi, penetration, colony, and overall success rates of individual spores failed to differentiate the parents 'Horizon' and V. cinerea B9 (Fig. 1D). In contrast at 8 to 9 dpi, visual ratings, incidence of sporulation, and hyphal transects all differentiated the parents by $30 \%$ or more (Fig. 1C and D). Length of the longest hyphae, also recorded at 8 to $9 \mathrm{dpi}$, failed to differentiate the controls or the parents (Fig. 1C).

Correlation matrix across years and data type. To assess the reproducibility across years and between controlled inoculation and vineyard infection, correlation matrices were constructed based on observations for all progeny (Tables 2 and 3). As expected, values within a sampling date tended to be more highly correlated regardless of data type, and values within a data type tended to be more highly correlated regardless of sampling date. For example, in the 11-3527 family among visual ratings, incidence of sporulation, and hyphal transects on 060214, correlation values ranged from 0.60 to 0.86 ; similarly, sampling dates involving visual ratings had correlation values ranging from 0.54 to 0.76 (Table 2). Similar observations held for NY09.0805 (Table 3). For both families, field ratings were more consistent within a growing season $(0.29$ to 0.68$)$ than among seasons ( 0.12 to 0.43$)$. In terms of correlation between lab and vineyard results for the 11-3527 family, hyphal transects and
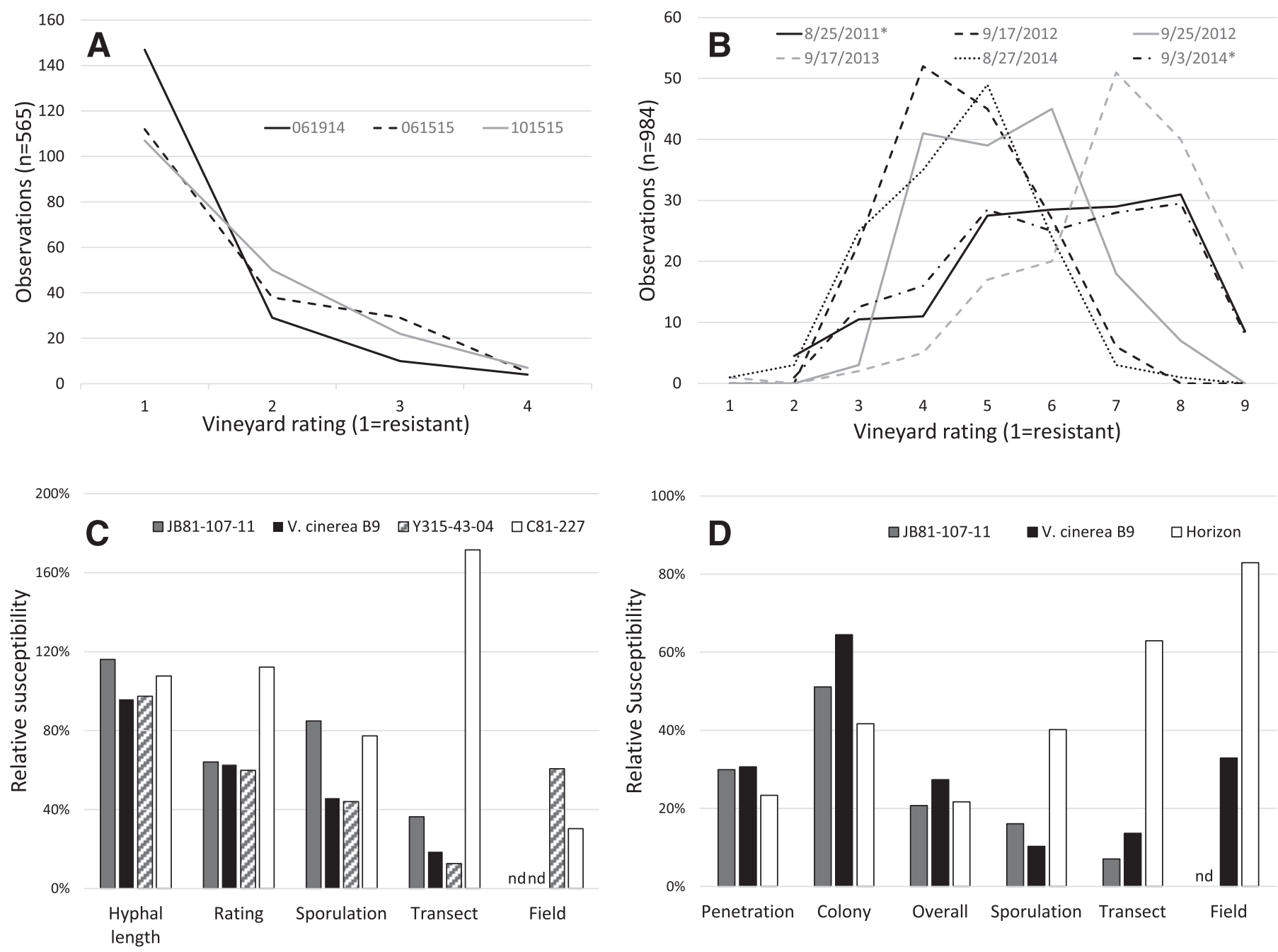

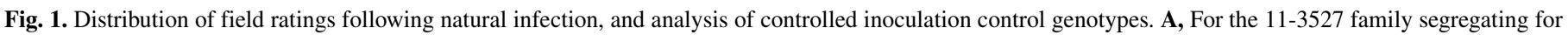

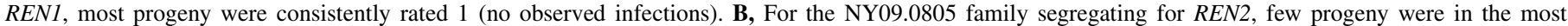

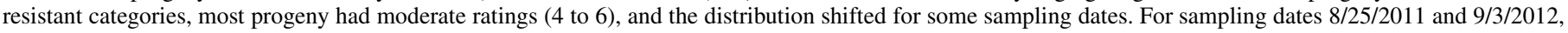

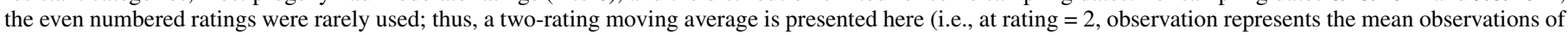

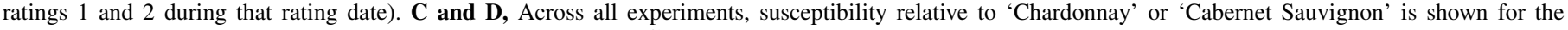

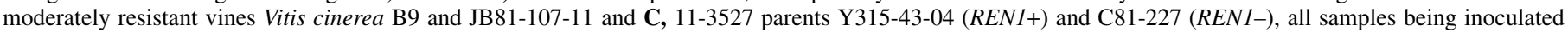

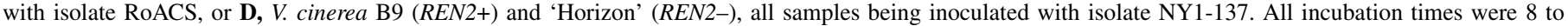
9 days postinoculation (dpi), except for 2 dpi penetration, colony, and overall success rates. nd $=$ not determined. 
visual ratings correlated with field ratings better than sporulation did (Table 2). In contrast for NY09.0805, 2 dpi penetration, colony, and overall success rates had the strongest correlation with field ratings, and correlations were best in the first year of field rating (Table 3).

Genetic analysis. GBS was used to construct genetic maps for both families. A total of 483,226 SNPs were identified for 284 confirmed progeny in the 11-3527 family. After filtering, 6,715 biallelic markers were input into JoinMap 4.1, and a map with the 19 expected linkage groups was obtained, including 2,176 nonredundant markers and representing a total genetic length of 3,793 cM. For NY09.0805, 331,356 SNPs were identified for 156 confirmed progeny. The HetMappS pipeline was used to generate parental maps, which contained 2,600 and 1,520 nonredundant markers, representing genetic lengths of 1,320 and 1,047 cM, respectively (Hyma et al. 2015).

These genetic maps were used for marker-trait analysis. REN1 was previously localized to chromosome 13 between 16.7 and 18.1 $\mathrm{Mb}$ in the PN40024 8X genome (Coleman et al. 2009), and here in all analyses involving the 11-3527 family, chromosome 13 had the most significant match. For 2012 hyphal transect data, heteroscedasticity analyses indicated the need for a cube root transformation, which resulted in a significant association at or near the reported REN1 locus (TransectT, Table 4). In subsequent years, nontransformed and transformed hyphal transects yielded similar results for QTL mapping, even for single trait multi-environment analysis (Table 4). Measuring the length of the longest hyphae had insufficient genetic basis, and the incidence of sporulation was not highly reproducible. Assessing powdery mildew severity at 8 to 9 dpi by either visual ratings or hyphal transects reproducibly identified the REN1 locus with high statistical significance. This locus was able to explain 27.1 to $74.1 \%$ of the phenotypic variance measured by these two approaches (Table 4), with similar results. In the vineyard, severity ratings in June 2014 and 2015 (not in October 2015) also identified the REN1 locus, but the significance and explained phenotypic variance was less than that for laboratory visual ratings or hyphal transects (Table 4). In the 11-3527 family, the REN2 locus had no significant association with data from any phenotyping approach.

For the multiple environment analysis of transects, the most adequate parsimonious model for the variance-covariance matrix ( $\Sigma$ ) was compound symmetry, according to the AIC and BIC criteria. This model has a covariance structure characterized by homogeneity of the variances; therefore, correlation among separate measurements exists, and this correlation is constant irrespective of the spatiotemporal separation of the measures. The multiple environment QTL model identified the REN1 locus using fewer individuals (42) than were analyzed in single environment analyses (105 to 124) (Table 4). In addition, no interaction between the locus and the experiments (environments) was found ( $P=0.461$ at $\alpha=0.05$ ).

REN2 was previously localized to chromosome 14 at ca. $27 \mathrm{Mb}$ (P. Barba, S. M. Park, and B. I. Reisch, personal communication), and here for the NY09.0805 family, hyphal transect and sporulation data identified the same locus, explaining 9.6 to $16.9 \%$ of the phenotypic variance (Table 4). No data collected at 2 dpi nor from any of the six field rating dates had sufficient genetic basis for detection of REN2. Field ratings indicated QTL on other chromosomes, but none was reproducible. Leaf pubescence made visual ratings impractical in the NY09.0805 family (Fig. 2).

Genome gazing for $\mathbf{R}$-gene candidates under QTL. REN1 was previously shown to span 11 full or truncated coiled-coil- (CC-) NB-LLR genes in the PN40024 version 8X reference genome (Jaillon et al. 2007), and REN2 had not been mapped since the development of the reference genome. Given that most resistance loci with dominant, qualitative inheritance co-localize with NLR

TABLE 2. Correlation of experiment data types for C81-227 ×Y315-43-04 (11-3527 family) progeny segregating for $R E N 1^{\mathrm{a}}$

\begin{tabular}{|c|c|c|c|c|c|c|c|c|c|c|c|c|c|c|}
\hline & $\begin{array}{c}\text { Longest hyphae } \\
091712\end{array}$ & $\begin{array}{l}\text { Transect } \\
091712\end{array}$ & $\begin{array}{c}\text { Sporulation } \\
091712\end{array}$ & $\begin{array}{l}\text { Transect } \\
072213\end{array}$ & $\begin{array}{l}\text { Rating } \\
072213\end{array}$ & $\begin{array}{c}\text { Sporulation } \\
072213\end{array}$ & $\begin{array}{l}\text { Transect } \\
052714\end{array}$ & $\begin{array}{l}\text { Rating } \\
052714\end{array}$ & $\begin{array}{l}\text { Transect } \\
060214\end{array}$ & $\begin{array}{l}\text { Rating } \\
060214\end{array}$ & $\begin{array}{l}\text { Sporulation } \\
060214\end{array}$ & $\begin{array}{l}\text { Field } \\
061514\end{array}$ & $\begin{array}{c}\text { Field } \\
061515\end{array}$ & $\begin{array}{c}\text { Field } \\
101515\end{array}$ \\
\hline \multicolumn{15}{|l|}{ Longest hyphae } \\
\hline 091712 & 1.00 & 0.41 & 0.48 & 0.39 & 0.50 & 0.15 & 0.22 & 0.24 & 0.31 & 0.28 & 0.21 & 0.21 & 0.15 & -0.03 \\
\hline Transect 091712 & 0.41 & 1.00 & 0.71 & 0.50 & 0.49 & 0.05 & 0.24 & 0.36 & 0.41 & 0.42 & 0.22 & -0.02 & 0.12 & 0.05 \\
\hline Sporulation 091712 & 0.48 & 0.71 & 1.00 & 0.43 & 0.43 & 0.04 & 0.13 & 0.19 & 0.38 & 0.34 & 0.21 & -0.03 & 0.13 & 0.03 \\
\hline Transect 072213 & 0.39 & 0.50 & 0.43 & 1.00 & 0.81 & 0.27 & 0.65 & 0.64 & 0.66 & 0.67 & 0.48 & 0.18 & 0.22 & 0.11 \\
\hline Rating 072213 & 0.50 & 0.49 & 0.43 & 0.81 & 1.00 & 0.24 & 0.53 & 0.54 & 0.63 & 0.64 & 0.48 & 0.14 & 0.16 & 0.01 \\
\hline Sporulation 072213 & 0.15 & 0.05 & 0.04 & 0.27 & 0.24 & 1.00 & 0.23 & 0.23 & 0.25 & 0.24 & 0.11 & 0.05 & 0.08 & -0.01 \\
\hline Transect 052714 & 0.22 & 0.24 & 0.13 & 0.65 & 0.53 & 0.23 & 1.00 & 0.77 & 0.67 & 0.69 & 0.45 & 0.32 & 0.23 & 0.19 \\
\hline Rating 052714 & 0.24 & 0.36 & 0.19 & 0.64 & 0.54 & 0.23 & 0.77 & 1.00 & 0.70 & 0.76 & 0.47 & 0.18 & 0.33 & 0.26 \\
\hline Transect 060214 & 0.31 & 0.41 & 0.38 & 0.66 & 0.63 & 0.25 & 0.67 & 0.70 & 1.00 & 0.86 & 0.65 & 0.22 & 0.27 & 0.18 \\
\hline Rating 060214 & 0.28 & 0.42 & 0.34 & 0.67 & 0.64 & 0.24 & 0.69 & 0.76 & 0.86 & 1.00 & 0.60 & 0.24 & 0.40 & 0.23 \\
\hline Sporulation 060214 & 0.21 & 0.22 & 0.21 & 0.48 & 0.48 & 0.11 & 0.45 & 0.47 & 0.65 & 0.60 & 1.00 & 0.16 & 0.10 & 0.08 \\
\hline Field 061514 & 0.21 & -0.02 & -0.03 & 0.18 & 0.14 & 0.05 & 0.32 & 0.18 & 0.22 & 0.24 & 0.16 & 1.00 & 0.39 & 0.43 \\
\hline Field 061515 & 0.15 & 0.12 & 0.13 & 0.22 & 0.16 & 0.08 & 0.23 & 0.33 & 0.27 & 0.40 & 0.10 & 0.39 & 1.00 & 0.61 \\
\hline Field 101515 & -0.03 & 0.05 & 0.03 & 0.11 & 0.01 & -0.01 & 0.19 & 0.26 & 0.18 & 0.23 & 0.08 & 0.43 & 0.61 & 1.00 \\
\hline
\end{tabular}

${ }^{a}$ Dates are shown as MMDDYY.

TABLE 3. Correlation of experiment data types for 'Horizon' $\times$ Vitis cinerea B9 (NY09.0805 family) progeny segregating for REN2a

\begin{tabular}{|c|c|c|c|c|c|c|c|c|c|c|c|c|c|}
\hline & $\begin{array}{c}\text { Penetration } \\
062512\end{array}$ & $\begin{array}{l}\text { Colony } \\
062512\end{array}$ & $\begin{array}{l}\text { Overall } \\
062512\end{array}$ & $\begin{array}{l}\text { Transect } \\
062314\end{array}$ & $\begin{array}{c}\text { Sporulation } \\
062314\end{array}$ & $\begin{array}{c}\text { Transect } \\
063014\end{array}$ & $\begin{array}{c}\text { Sporulation } \\
063014\end{array}$ & $\begin{array}{c}\text { Field } \\
082511\end{array}$ & $\begin{array}{c}\text { Field } \\
091712\end{array}$ & $\begin{array}{c}\text { Field } \\
092512\end{array}$ & $\begin{array}{c}\text { Field } \\
091713\end{array}$ & $\begin{array}{c}\text { Field } \\
082714\end{array}$ & $\begin{array}{c}\text { Field } \\
090314\end{array}$ \\
\hline Penetration 062512 & 1.00 & 0.76 & 0.99 & 0.18 & 0.39 & 0.38 & 0.34 & 0.32 & 0.37 & 0.25 & -0.02 & 0.15 & 0.10 \\
\hline Colony 062512 & 0.76 & 1.00 & 0.79 & 0.21 & 0.41 & 0.32 & 0.32 & 0.42 & 0.32 & 0.19 & 0.13 & 0.19 & 0.11 \\
\hline Overall 062512 & 0.99 & 0.79 & 1.00 & 0.18 & 0.39 & 0.37 & 0.34 & 0.36 & 0.41 & 0.28 & 0.00 & 0.17 & 0.10 \\
\hline Transect 062314 & 0.18 & 0.21 & 0.18 & 1.00 & 0.49 & 0.53 & 0.47 & 0.20 & 0.00 & 0.04 & 0.10 & 0.09 & 0.05 \\
\hline Sporulation 062314 & 0.39 & 0.41 & 0.39 & 0.49 & 1.00 & 0.42 & 0.42 & 0.24 & 0.03 & 0.08 & 0.01 & 0.11 & 0.05 \\
\hline Transect 063014 & 0.38 & 0.32 & 0.37 & 0.53 & 0.42 & 1.00 & 0.70 & 0.29 & 0.10 & 0.14 & 0.17 & 0.19 & 0.18 \\
\hline Sporulation 063014 & 0.34 & 0.32 & 0.34 & 0.47 & 0.42 & 0.70 & 1.00 & 0.24 & 0.11 & 0.04 & 0.14 & 0.21 & 0.14 \\
\hline Field 082511 & 0.32 & 0.42 & 0.36 & 0.20 & 0.24 & 0.29 & 0.24 & 1.00 & 0.12 & 0.19 & 0.25 & 0.25 & 0.20 \\
\hline Field 091712 & 0.37 & 0.32 & 0.41 & 0.00 & 0.03 & 0.10 & 0.11 & 0.12 & 1.00 & 0.68 & 0.22 & 0.29 & 0.25 \\
\hline Field 092512 & 0.25 & 0.19 & 0.28 & 0.04 & 0.08 & 0.14 & 0.04 & 0.19 & 0.68 & 1.00 & 0.29 & 0.34 & 0.34 \\
\hline Field 091713 & -0.02 & 0.13 & 0.00 & 0.10 & 0.01 & 0.17 & 0.14 & 0.25 & 0.22 & 0.29 & 1.00 & 0.33 & 0.36 \\
\hline Field 082714 & 0.15 & 0.19 & 0.17 & 0.09 & 0.11 & 0.19 & 0.21 & 0.25 & 0.29 & 0.34 & 0.33 & 1.00 & 0.29 \\
\hline Field 090314 & 0.10 & 0.11 & 0.10 & 0.05 & 0.05 & 0.18 & 0.14 & 0.20 & 0.25 & 0.34 & 0.36 & 0.29 & 1.00 \\
\hline
\end{tabular}

${ }^{a}$ Dates are shown as MMDDYY. 
clusters, previously published NLR sequences (Yang et al. 2008) were used to BLAT query the PN40024 version 12X.2 genome in the region defined by the 1.8-LOD intervals to identify candidate genes. Under REN1, 9 query sequences matched 10 locations by BLAT (Table 5), but by BLAST all matched the same NLR annotation around $18.56 \mathrm{Mb}$ on chromosome 13 (Table 6). Under REN2, 2 query sequences matched 2 locations on chromosome 14 by BLAT (Table 5 ), with BLAST indicating one NLR annotation around $27.24 \mathrm{Mb}$ and a region lacking gene annotation around 25.86 Mb (Table 6).

\section{DISCUSSION}

In the genetic mapping of host resistance genes, the methods by which phenotypic data are collected can be as important as the genetic design or analysis of the experiment. If the goal is to explain the heritable variation in resistance, then the best phenotyping method is that which best reveals the underlying genetics. Here, we leveraged the grape genome to develop high resolution genetic maps, which we used to evaluate a number of different phenotyping strategies in vineyards and in controlled environments within a phenotyping center. We focused on two previously mapped resistance sources to validate our methods relative to conventional phenotyping approaches.

What did not work. The biggest surprises came from what did not work. While penetration and colony success rates at 2 dpi are frequently used to characterize resistance mechanisms (Gadoury et al. 2012a; Ramming et al. 2012; Weßling and Panstruga 2012), including quantitative resistance mechanisms in Vitis (Barba et al. 2015; Feechan et al. 2015), this approach failed to identify QTL here (Table 4) or in other grapevine families (L. Cadle-Davidson, D. Gadoury, J. Fresnedo-Ramírez, S. Yang, J. Luby, and B. Reisch, unpublished data). A possible explanation is that the stress experienced prior to sampling in the vineyard environment or during sample handling and preparation can induce transitory resistance. Phenotyping for resistance to biotrophic pathogens requires careful

TABLE 4. Significance and phenotypic variance explained by quantitative trait loci (QTL) for various data types at each sampling date (MMDDYY)

\begin{tabular}{|c|c|c|c|c|c|c|c|c|c|}
\hline Locus & Date & Data type $^{\mathrm{a}}$ & Number of progeny ${ }^{\mathrm{a}}$ & $\mathrm{Chr}^{\mathrm{b}}$ & LOD score ${ }^{c}$ & Threshold of $\mathrm{LOD}^{\mathrm{c}}$ & Peak physical position $^{c}$ & LOD interval $(\mathrm{Mb})^{\mathrm{c}}$ & $R^{2 \mathrm{c}}$ \\
\hline \multirow[t]{23}{*}{ REN1 } & 091712 & & & & & & & & \\
\hline & & Longest hyphae & 121 & 13 & 4.20 & 5.10 & NA & NA & NA \\
\hline & & Sporulation & 100 & 13 & 5.87 & 5.28 & $14,509,637$ & $13.07-15.17$ & 26.6 \\
\hline & & Transect & 105 & 13 & 4.80 & 5.75 & NA & NA & NA \\
\hline & & Transect $^{\mathrm{d}}$ & 105 & 13 & 8.25 & 5.27 & $14,509,637$ & $14.51-16.73$ & 27.1 \\
\hline & 072213 & & & & & & & & \\
\hline & & Sporulation & 124 & 13 & 1.01 & 8.37 & NA & NA & NA \\
\hline & & Rating & 124 & 13 & 13.27 & 5.30 & $16,718,457$ & $15.18-18.43$ & 45.9 \\
\hline & & Transect & 124 & 13 & 20.98 & 5.05 & $18,442,835$ & $18.43-18.52$ & 53.9 \\
\hline & & TransectT & 124 & 13 & 15.26 & 5.10 & $18,300,393$ & $18.10-18.44$ & 46.2 \\
\hline & 052714 & & & & & & & & \\
\hline & & Rating & 115 & 13 & 15.85 & 5.06 & $18,300,393$ & $16.73-18.44$ & 57.9 \\
\hline & & Transect & 115 & 13 & 19.12 & 5.23 & $18,300,393$ & $15.19-18.43$ & 53.8 \\
\hline & & TransectT & 115 & 13 & 21.47 & 5.24 & $18,300,393$ & $15.19-18.43$ & 55.9 \\
\hline & 060214 & Sporulation & 116 & 13 & 8.32 & 5.29 & $18,225,176$ & $15.18-18.43$ & 14.4 \\
\hline & & Rating & 115 & 13 & 17.80 & 5.14 & $18,442,835$ & $18.43-18.97$ & 74.1 \\
\hline & & Transect & 113 & 13 & 20.54 & 5.16 & $18,431,192$ & $16.73-18.44$ & 51.3 \\
\hline & & TransectT & 113 & 13 & 17.23 & 5.20 & $18,300,393$ & $16.72-18.44$ & 54.9 \\
\hline & All dates & & & & & & & & \\
\hline & & Transect & 42 & 13 & 20.53 & 3.67 & $18,972,992$ & $16.72-20.63$ & 37.0 \\
\hline & 061514 & Field & 148 & 13 & 7.39 & 5.48 & $16,718,453$ & $15.08-18.10$ & 18.4 \\
\hline & 061515 & Field & 142 & 13 & 6.43 & 5.31 & $16,718,457$ & $15.18-18.23$ & 18.9 \\
\hline & 101515 & Field & 145 & 13 & 3.58 & 5.29 & NA & NA & NA \\
\hline \multirow[t]{18}{*}{ REN2 } & 062512 & & & & & & & & \\
\hline & & Penetration & 85 & 14 & 0.10 & 4.06 & NA & NA & NA \\
\hline & & Colony & 85 & 14 & 0.57 & 3.98 & NA & NA & NA \\
\hline & & Overall & 85 & 14 & 0.65 & 4.14 & NA & NA & NA \\
\hline & 062314 & & & & & & & & \\
\hline & & Sporulation & 114 & 14 & 1.22 & 3.76 & NA & NA & NA \\
\hline & & Transect & 135 & 14 & 5.23 & 3.47 & $27,119,627$ & $24.52-29.54$ & 9.6 \\
\hline & & TransectT & 135 & 14 & 4.17 & 3.22 & $27,119,627$ & $26.39-28.68$ & 11.7 \\
\hline & & Sporulation & 117 & 14 & 7.51 & 3.96 & $25,628,594$ & $23.16-25.68$ & 16.9 \\
\hline & & Transect & 117 & 14 & 3.27 & 3.85 & NA & NA & NA \\
\hline & & TransectT & 117 & 14 & 3.50 & 2.98 & $28,532,928$ & $24.52-29.54$ & 12.7 \\
\hline & 082511 & Field & 154 & 3 & 9.14 & 3.39 & $14,987,335$ & $3.76-18.75$ & 23.9 \\
\hline & 091712 & Field & 152 & 14 & 1.04 & 3.40 & NA & NA & NA \\
\hline & 092512 & Field & 151 & 14 & 1.25 & 3.33 & NA & NA & NA \\
\hline & 091713 & Field & 149 & 4 & 3.69 & 3.40 & $2,929,080$ & $2.11-20.70$ & 9.6 \\
\hline & 091713 & Field & 149 & 15 & 3.60 & 3.40 & $6,019,367$ & $3.97-8.48$ & 9.4 \\
\hline & 082714 & Field & 148 & 2 & 3.97 & 3.34 & $5,510,928$ & $1.90-12.78$ & 11.6 \\
\hline & 090314 & Field & 154 & 14 & 0.72 & 3.36 & NA & NA & NA \\
\hline
\end{tabular}

${ }^{a}$ Data types are defined in the Methods. For REN1 All Dates Transect, only the 42 progeny that were evaluated in all four sampling dates were included in the multiple environment analysis. Number of progeny here is fewer than the total number phenotyped, as QTL analysis represents an intersect join of the sets of individuals contributing to the genetic map and of individuals with phenotypic data.

b REN1 was previously localized to chromosome (Chr) 13 and REN2 to Chr 14. All significant QTL are shown here, and when no significant QTL were identified, the highest LOD value on the target $\mathrm{Chr}$ is listed and remaining data are listed as NA.

${ }^{c}$ Statistically significant when the highest LOD score (associated with peak physical position) surpasses the LOD threshold. LOD interval refers to 1.8-LOD support interval. All physical positions are from the PN40024 reference genome version 12X.2. $R^{2}$ (coefficient of determination) is the percentage of phenotypic variance explained by the QTL.

d TransectT represents the cube-root transformed hyphal transect. 
consideration of how predisposition (Bostock et al. 2014) may affect the observed responses. For example, Moyer et al. (2015) reported transient stress-induced disease resistance (SIDR) against powdery mildew on ordinarily susceptible young leaves of $V$. vinifera 'Chardonnay' exposed to acute overnight low temperatures (e.g., $<8^{\circ} \mathrm{C}$ ). For the mapping families and methods used here, if SIDR from cold or other stresses had a large or genotype-dependent effect, it may have prevented the detection of resistance QTL at early but not later developmental stages. Regardless of the reason, phenotyping at 8 to 9 dpi resulted in much more reproducible and heritable results than phenotyping at $2 \mathrm{dpi}$.

While longer incubation times generally resulted in assessments of host responses that were indicative of the underlying genetics of resistance, not all data types summarized the resistance biology and genetics effectively. Previously, for resistance from 'Tamiami' and from JB81-107-11, hyphal length at 3 dpi indicated significant differences between resistant and susceptible responses (Ramming et al. 2012). Here, measuring hyphal length at 8 to 9 dpi, we were unable to detect significant differences among control genotypes (Fig. 1) and failed to detect REN1 (Table 4). Hyphal length could work for some resistance mechanisms but not others, or it could require earlier observation, such as at 3 dpi.

The other surprise was the outcome of field ratings. We expected to explain less variance and not to identify known QTL in all experiments (as occurred with REN1), but never identifying the $R E N 2$ locus with field ratings was unexpected. Given that REN2 is known to be race-specific and has been used in the Cornell breeding vineyard since 1988, E. necator isolates virulent on REN2 have likely been selected, raising a key point: for field evaluations likely involving race specificity, phenotyping should done soon after introduction of the resistance source to enhance the likelihood of detecting QTL. Consistent with this, REN1 has only been used in the ARS-Parlier breeding program since 2010, and we were able to detect that locus using field ratings. Along these lines, GBS-derived amplicon sequencing (AmpSeq) markers specific to the REN2 locus were not validated using the recent field ratings presented here (L. Cadle-Davidson and B. I. Reisch, unpublished data), but were validated with 11 years of older phenotype data for a related REN2 family ('Horizon' $\times$ Illinois 547-1) (Yang et al. 2016b). This supports the concept that over time the phenotypic variance explained by racespecific genetics can decline in field conditions, and emphasizes that controlled phenotyping for genetic analysis explains small or large components of resistance in some but not all complex environments. Further, as with most evaluations of large, long-lived perennials, field phenotyping as described here may also be limited by: (i) use of single plants in unreplicated plots, and (ii) close spacing between plants, making it difficult to distinguish adjacent plants when rating. While it might be useful to replicate vines for genetic studies, both within locations and among additional locations, breeders are limited by practical considerations of space, funding, and availability of propagules from young seedlings.

While rating scales are commonly used to evaluate field resistance and can be simpler to use than continuous measures, rating categorization necessitates loss of data reflecting continuous variation (Williams 1989); this is typically not a problem for qualitative resistance phenotypes, but may reduce the ability to detect quantitative resistance genes. Field ratings evaluate resistance at different points within or between epidemics, and QTL detected early in an epidemic may reflect variation between individuals with and without resistance genes, whereas late QTL may reflect the variation among susceptible individuals, exemplified by the SEN1 locus from 'Chardonnay' (Barba et al. 2014). Here we detected resistance from REN1 in June but failed to detect significant QTL in October. While more effort is needed in the design of phenotyping experiments for natural infection, clearly there is value in collecting data multiple times across multiple environments.

What the genetic analyses taught us about the phenotypes. The best results were obtained 8 to $9 \mathrm{dpi}$ as measured by visual ratings or by hyphal transects. Hyphal transect is a point-intercept measure developed here as an objective assessment of colony
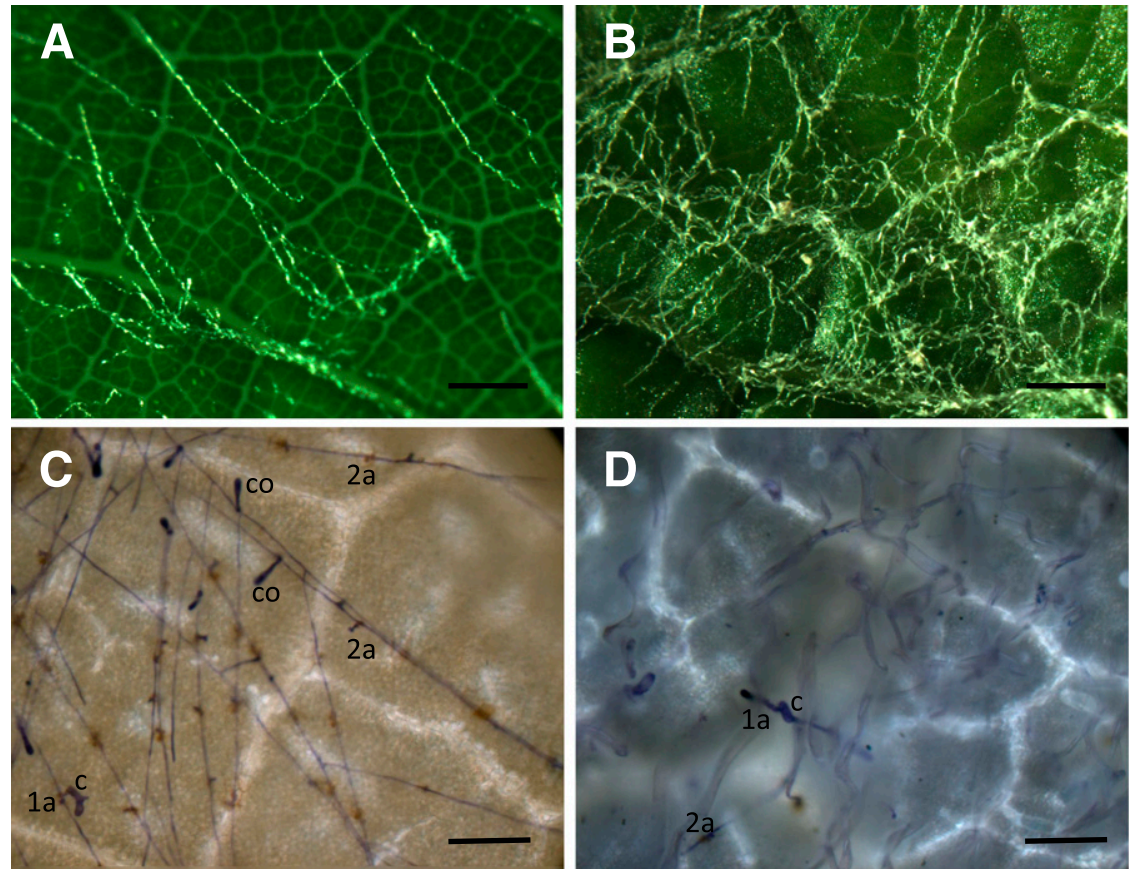

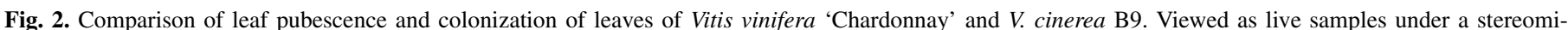

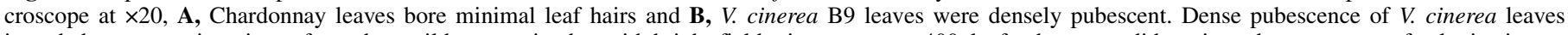

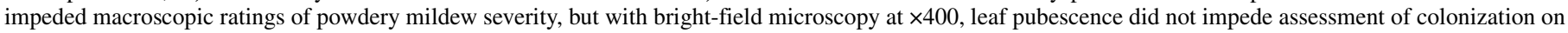

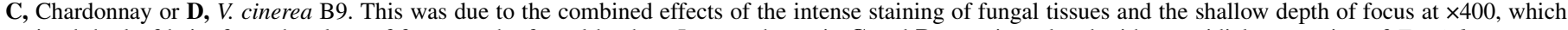

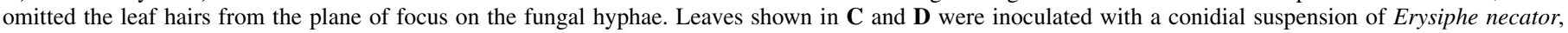

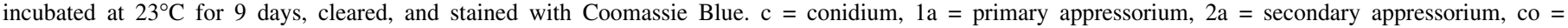
conidiophore. Scale bars in $\mathbf{A}$ and $\mathbf{B}$ indicate $1 \mathrm{~mm}$. Scale bars in $\mathbf{C}$ and $\mathbf{D}$ indicate $100 \mu \mathrm{m}$. 
density. Regardless of whether a resistant line has penetration resistance, programmed cell death-mediated posthaustorial resistance, or simply slows colonization, fewer hyphae will cross the transects, reflecting less dense colonization. While sporulation is related to colony density (Gadoury et al. 2012b), sporulation incidence data produced variable results. Importantly, with each year our ability to explain phenotypic variance improved: with the continuous variable hyphal transects increasing from 27\% in 2012 to $55 \%$ in 2014 and the categorical variable visual ratings increasing from $46 \%$ in 2013 to $74 \%$ in 2014 (Table 4). This may reflect continual efforts to standardize sampling, handling, processing, and rating.

In the ARS-Parlier vineyard, C81-227 (thought to be REN2+) is typically more resistant than Y315-43-04 (REN1+), but C81-227 was susceptible in controlled inoculations here (Fig. 1C). This disparity is likely due to the E. necator isolate RoaCS used for evaluation. Prior to processing full experiments, we run a preliminary experiment to identify which isolate provides the greatest separation between parent phenotypes, assuming this will maximize the distribution of phenotypes in the progeny. We did so without knowing C81-227 may be REN2+. Thus, RoaCS is very likely virulent on $R E N 2$, which also explains why we failed to detect the $R E N 2$ locus in this family in controlled inoculations. We have since invested additional effort for detection of REN2 using vineyard data for the 11-3527 family, and using targeted methods not described here, the locus explained $4.8 \%$ of the variance in the October 2015 rating date, justifying additional investigation (J. FresnedoRamírez, Q. Sun, D. Gadoury, C. Ledbetter, and L. Cadle-Davidson, unpublished data). While REN2 is clearly race specific, previous results have suggested it may be useful to enhance the durability of RUN1 resistance (Feechan et al. 2015).

Leveraging the genome for genetic analyses. Though phenotyping is the focus here, the tools implemented for genetic analyses are not trivial. GBS data leverage the power of the genome but present

TABLE 5. BLAT output

\begin{tabular}{|c|c|c|c|c|c|c|}
\hline \multirow[b]{2}{*}{ Locus } & \multirow[b]{2}{*}{ NLR querya } & \multirow[b]{2}{*}{ Score } & \multirow{2}{*}{$\begin{array}{l}\text { Query } \\
\text { size }\end{array}$} & \multicolumn{2}{|c|}{ Coordinates $^{\mathrm{b}}$} & \multirow{2}{*}{$\begin{array}{l}\text { Alignment } \\
\text { length (bp) }\end{array}$} \\
\hline & & & & Start & End & \\
\hline \multicolumn{7}{|l|}{ REN1 } \\
\hline & XNL03766 & 17 & 1,032 & 13530990 & 13531040 & 51 \\
\hline & XNL03230 & 15 & 944 & 14178454 & 14178498 & 45 \\
\hline & XN33892 & 192 & 193 & 16951830 & 16957020 & 5,191 \\
\hline & CNL33889 & 1,112 & 1,130 & 16987924 & 16992065 & 4,142 \\
\hline & CNL33887 & 899 & 902 & 17039148 & 17084277 & 45,130 \\
\hline & XNL25223 & 38 & 1,069 & 17353235 & 17353348 & 114 \\
\hline & CNL01662 & 1,201 & 1,214 & 17686538 & 17690713 & 4,176 \\
\hline & CN25707 & 16 & 603 & 18382585 & 18382632 & 48 \\
\hline & CNL02054 & 1,211 & 1,211 & 18564209 & 18567841 & 3,633 \\
\hline \multicolumn{7}{|c|}{ REN2 } \\
\hline & CNL2 & 14 & 1,232 & 25757331 & 25757372 & 42 \\
\hline & XN33318_A & 14 & 373 & 25863345 & 25863386 & 42 \\
\hline
\end{tabular}

a From Yang et al. 2008.

b Physical position according to Grape Reference Genome version $12 X .2$ challenges for highly heterozygous species, among them missing data and heterozygote undercalling. The HetMappS pipeline overcame those challenges in constructing parental linkage maps for NY09.0805 (Hyma et al. 2015). However, the HetMappS pipeline failed to return a sufficient number of markers for the 11-3527 family (J. Fresnedo-Ramírez, L. Cadle-Davidson, C. Ledbetter, and Q. Sun, unpublished data). Therefore, an integrated map was developed for 11-3527, combining: (i) a $\chi^{2}$ goodness-of-fit test to identify pseudo-testcross and intercross markers, validated with progenitor genotypes, and (ii) map construction in JoinMap 4.1 using the multipoint maximum likelihood mapping algorithm. The two approaches to map construction resulted in similar resolution, but the integrated linkage map enabled application of mixed linear models for multiple environment QTL mapping and variance partitioning.

The high resolution of markers and the quality of the hyphal transect data enabled the REN1 and REN2 QTL to be defined to relatively narrow intervals_as small as $90 \mathrm{~kb}$ for REN1 in 2013 (Table 4). This allowed a candidate gene approach to identify NLR genes underlying the QTL. The REN1 QTL peak was reproducibly localized at 18.30 to $18.44 \mathrm{Mb}$ on chromosome 13 , and the only NLR identified in the most broadly defined range of the QTL was at $18.56 \mathrm{Mb}$. In two experiments, the REN2 QTL peak varied between 25.63 and $28.53 \mathrm{Mb}$ on chromosome 14, and the two NLR genes we identified in the most broadly defined range of the QTL were at 25.86 and $27.22 \mathrm{Mb}$. Given the high diversity of Vitis spp., the REN1 and REN2 loci may have structural rearrangements relative to the PN40024 reference genome, but this quick analysis demonstrates the power of high-resolution GBS maps for quickly narrowing in on candidate genes at a locus. Given that all known resistance loci against E. necator, aside from REN1, are sourced from wild Vitis spp., reference genomes of Vitis spp. are important for such analyses.

Mixed models were used here for multiple environment genetic analysis due to their flexibility to model variance-covariance structures. This approach may minimize the over-estimation of QTL number and effect sizes (Piepho 2005). Through this analysis, we objectively determined hyphal transects provide reproducible data, validated by the nonsignificant REN1 QTL-experiment interaction. By simply adjusting the context of environment, this multiple environment QTL analysis has several applications in host resistance genetics: in stacking resistance loci and estimating the effect sizes of every locus, in testing for race and environment specificity, in joint analysis of disease resistance with other traits, and in detecting minor components contributing to resistance. However, larger sample sizes are needed (>200 individuals in the case of diploid outcrossing $F_{1}$ families, such as grape), and the same set of individuals should be phenotyped in all environments.

Is resistance phenotyping a lost art? As science and technologies advance, there is a constant pressure to work on the cutting edge, raising the possibility that historically accumulated knowledge and skills are lost. Certainly, in the early days of the genomics era, there was little love for phenotyping. In looking across crops to

TABLE 6. Annotation of candidate R-genes underlying QTL in PN40024 version 12 X.2 reference genome

\begin{tabular}{|c|c|c|c|c|c|}
\hline Locus & NLR query ${ }^{\mathrm{a}}$ & Target locus name & Target description & Target coordinates & Target length \\
\hline \multicolumn{6}{|l|}{ REN1 } \\
\hline & $\begin{array}{l}\text { All nine query } \\
\text { sequences }\end{array}$ & GSVIVG01036582001 & $\begin{array}{l}\text { LOC_Os08g43010.1 } \\
\text { Disease resistance RPP13-like } \\
\text { protein 1, putative, expressed }\end{array}$ & chr13:18564299...18567841 (- strand) & 3,543 bp \\
\hline REN2 & CNL28679 & GSVIVG01032422001 & $\begin{array}{l}\text { LOC_Os } 08 \mathrm{~g} 32880.1 \\
\text { Disease resistance protein RPM1, } \\
\text { putative, expressed }\end{array}$ & chr14:27220418...27243618 (+ strand) & $23,201 \mathrm{bp}$ \\
\hline
\end{tabular}

\footnotetext{
${ }^{a}$ Each of the 11 query sequences that matched the REN1 or REN2 QTL region in the PN40024 version $12 X .2$ reference genome were submitted to retrieve functional annotations via BLAST queries of PN40024 at Phytozome 11 (https://phytozome.jgi.doe.gov/pz/portal.html), matching the Target annotations presented here. For REN1, all nine query sequences from Table 5 matched within these Target coordinates.
} 
identify publications of other controlled approaches to reproducibly phenotyping powdery mildew resistance on a quantitative scale, such studies are obscured in the background of field ratings on 4-, 5-, or 9-point scales, which have strengths and weaknesses described above. Most functional genetic studies use either the 2 dpi approach presented here, hallmarks of resistance such as indicators of cell death, or fail to carefully describe the observed phenotype. Those seeking improved phenotyping approaches to keep pace with genomic advances would be well-served by revisiting older literature where the details of environment, inoculum dose, pathogen genotype, leaf age, and response variables are thoughtfully considered in the experimental design (Nass et al. 1981; Williams 1989). Regardless of which phenotyping approach is deemed best, the results of genomicsbased breeding efforts will still require field validation to assure that newly produced cultivars have field-proven resistance.

\section{ACKNOWLEDGMENTS}

We thank P. Appleton, J. Lillis, B. Weldon, M. J. Welser, and numerous summer scholars, students, and visiting scientists for phenotyping support; K. Hyma for previously published contributions to the NY09.0805 parental maps; N. Ambriz and J. Andresen for 11-3527 vine maintenance and sampling; and S. Luce and A. Green for NY09.0805 vine maintenance and sampling. The U.S. Department of Agriculture, National Institute of Food and Agriculture, Specialty Crop Research Initiative provided funding for this project (award 2011-51181-30635). The National Grape and Wine Initiative provided funding for S. Yang. Mention of trade names or commercial products is solely for the purpose of providing specific information and does not imply recommendation or endorsement by the U.S. Department of Agriculture. USDA is an equal opportunity provider and employer.

\section{LITERATURE CITED}

Barba, P., Cadle-Davidson, L., Galarneau, E., and Reisch, B. 2015. Mechanisms of quantitative resistance to Erysiphe necator in Vitis rupestris B38. Phytopathology 105:1097-1103.

Barba, P., Cadle-Davidson, L., Harriman, J., Glaubitz, J. C., Brooks, S., Hyma, K., and Reisch, B. 2014. Grapevine powdery mildew resistance and susceptibility loci identified on a high-resolution SNP map. Theor. Appl. Genet. 127:73-84

Boer, M. P., Malosetti, M., Welham, S. J., and Thissen, J. T. N. M. 2014. Part 2: Statistical genetics and QTL estimation. In: The Guide to GenStat Release 17. R. W. Payne, S. A. Harding, D. A. Murray, D. M. Soutar, D. B. Baird, A. I. Glaser, S. J. Welham, A. R. Gilmour, R. Thompson, and R. Webster, eds. VSN International, Hemel, Hempstead, UK

Boer, M. P., Wright, D., Feng, L., Podlich, D. W., Luo, L., Cooper, M., and van Eeuwijk, F. A. 2007. A mixed-model quantitative trait loci (QTL) analysis for multiple-environment trial data using environmental covariables for QTL-by-environment interactions, with an example in maize. Genetics 177:1801-1813.

Bostock, R. M., Pye, F., and Roubtsova, T. V. 2014. Predisposition in plant disease: Exploiting the nexus in abiotic and biotic stress perception and response. Annu. Rev. Phytopathol. 52:517-549.

Broman, K. W., Wu, H., Sen, S., and Churchill, G. A. 2003. R/qtl: QTL mapping in experimental crosses. Bioinformatics 19:889-890.

Cadle-Davidson, L., Chicoine, D. R., and Consolie, N. C. 2011. Variation within and between Vitis species for foliar resistance to the powdery mildew pathogen Erysiphe necator. Plant Dis. 95:202-211.

Coleman, C., Copetti, D., Cipriani, G., Hoffmann, C., Kozma, P., Kovács, L., Morgante, M., Testolin, R., and Di Gaspero, G. 2009. The powdery mildew resistance gene REN1 co-segregates with an NBS-LRR gene cluster in two Central Asian grapevines. BMC Genet. 10:89.

Dalbò, M. A., Ye, G. N., Weeden, N. F., Wilcox, W. F., and Reisch, B. I. 2001. Marker-assisted selection for [REN2] powdery mildew resistance in grapes. J. Am. Soc. Hortic. Sci. 126:83-89.

Danecek, P., Auton, A., Abecasis, G., Albers, C. A., Banks, E., DePristo, M. A., Handsaker, R. E., Lunter, G., Marth, G. T., Sherry, S. T., McVean, G., and Durbin, R. 2011. The variant call format and VCF tools. Bioinformatics 27:2156-2158.

Dangl, J. L., Horvath, D. M., and Staskawicz, B. J. 2013. Pivoting the plant immune system from dissection to deployment. Science 341:746-751.

Elshire, R. J., Glaubitz, J. C., Sun, Q., Poland, J. A., Kawamoto, K., Buckler, E. S., and Mitchell, S. E. 2011. A robust, simple genotyping-by-sequencing (GBS) approach for high diversity species. PLoS One 6:e19379.
Feechan, A., Anderson, C., Torregrosa, L., Jermakow, A., Mestre, P., Wiedemann-Merdinoglu, S., Merdinoglu, D., Walker, A. M., Cadle-Davidson, L., Reisch, B. I., Aubourg, S., Bentahar, N., Shrestha, B., Bouquet, A., Adam-Blondon, A.-F., Thomas, M. R., and Dry, I. 2013. Genetic dissection of a TIR-NBS-LRR locus from the wild North American grapevine species Muscadinia rotundifolia identifies paralogous genes conferring resistance to major fungal and oomycete pathogens in cultivated grapevine. Plant J. 76: 661-674.

Feechan, A., Kocsis, M., Riaz, S., Zhang, W., Gadoury, D. M., Walker, A. M., Dry, I. B., Reisch, B. I., and Cadle-Davidson, L. 2015. Strategies for RUN1 deployment using RUN2 and REN2 to manage grapevine powdery mildew informed by studies of race-specificity. Phytopathology 105:1104-1113.

Frenkel, O., Brewer, M., and Milgroom, M. 2010. Variation in pathogenicity and aggressiveness of Erysiphe necator from different Vitis species and geographic origins in the eastern United States. Phytopathology 100: 1185-1193.

Gadoury, D. M., Cadle-Davidson, L., Wilcox, W. F., Dry, I. B., Seem, R. C., and Milgroom, M. G. 2012a. Grapevine powdery mildew (Erysiphe necator): A fascinating system for the study of the biology, ecology, and epidemiology of an obligate biotroph. Mol. Plant Pathol. 13:1-16.

Gadoury, D. M., Seem, R. C., Ficke, A., and Wilcox, W. F. 2003. Ontogenic resistance to powdery mildew in grape berries. Phytopathology 93:547-555.

Gadoury, D. M., Wakefield, L. M., Cadle-Davidson, L., Dry, I. B., and Seem, R. C. 2012b. Effects of prior vegetative growth, inoculum density, light, and mating on conidiation of Erysiphe necator. Phytopathology 102:65-72.

Gee, C. T., Gadoury, D. M., and Cadle-Davidson, L. 2008. Ontogenic resistance to Uncinula necator varies by genotype and tissue-type in a diverse collection of grapevine (Vitis spp.). Plant Dis. 92:1067-1073.

Glaubitz, J. C., Casstevens, T. M., Lu, F., Harriman, J., Elshire, R. J., Sun, Q., and Buckler, E. S. 2014. TASSEL-GBS: A high capacity genotyping by sequencing analysis pipeline. PLoS One 9:e90346.

Guttman, D. S., McHardy, A. C., and Schulze-Lefert, P. 2014. Microbial genome-enabled insights into plant-microorganism interactions. Nat. Rev. Genet. 15:797-813.

Hoffmann, S., Di Gaspero, G., Kovács, L., Howard, S., Kiss, E., Galbács, Z., Testolin, R., and Kozma, P. 2008. Resistance to Erysiphe necator in the grapevine 'Kishmish vatkana' is controlled by a single locus [REN1] through restriction of hyphal growth. Theor. Appl. Genet. 116:427-438.

Hyma, K. E., Barba, P., Wang, M., Londo, J. P., Acharya, C., Mitchell, S. E., Sun, Q., Reisch, B. I., and Cadle-Davidson, L. 2015. Heterozygous mapping strategy (HetMappS) for high resolution genotyping-by-sequencing markers: A case study in grapevine. PLoS One 10:e0134880.

IPGRI, UPOV, and OIV. 1997. Descriptors for grapevine (Vitis spp.). Edited by G. International Union for the Protection of New Varieties of Plants, Switzerland/Office International de la Vigne et du Vin, Paris, France/ International Plants Genetics Resources Institute, Rome, Italy.

Jaillon, O., Aury, J. M., Noel, B., Policriti, A., Clepet, C., Casagrande, A., Choisne, N., Aubourg, S., Vitulo, N., Jubin, C., Vezzi, A., Legeai, F., Hugueney, P., Dasilva, C., Horner, D., Mica, E., Jublot, D., Poulain, J., Bruyere, C., Billault, A., Segurens, B., Gouyvenoux, M., Ugarte, E., Cattonaro, F., Anthouard, V., Vico, V., Del Fabbro, C., Alaux, M., Di Gaspero, G., Dumas, V., Felice, N., Paillard, S., Juman, I., Moroldo, M., Scalabrin, S., Canaguier, A., Le Clainche, I., Malacrida, G., Durand, E., Pesole, G., Laucou, V., Chatelet, P., Merdinoglu, D., Delledonne, M., Pezzotti, M., Lecharny, A., Scarpelli, C., Artiguenave, F., Pe, M. E., Valle, G., Morgante, M., Caboche, M., Adam-Blondon, A. F., Weissenbach, J., Quetier, F., and Wincker, P., and French-Italian Public Consortium for Grapevine Genome. 2007. The grapevine genome sequence suggests ancestral hexaploidization in major angiosperm phyla. Nature 449:463-467.

$\mathrm{Li}$, J., and Ji, L. 2005. Adjusting multiple testing in multilocus analyses using the eigenvalues of a correlation matrix. Heredity 95:221-227.

Li, H., and Durbin, R. 2009. Fast and accurate short read alignment with Burrows-Wheeler transform. Bioinformatics 25:1754-1760.

Lynch, M., and Walsh, B. 1998. Genetics and Analysis of Quantitative Traits. Sinauer, Sunderland, MA

Malosetti, M., Ribaut, J. M., Vargas, M., Crossa, J., and Eeuwijk, F. A. 2007. A multi-trait multi-environment QTL mixed model with an application to drought and nitrogen stress trials in maize (Zea mays L.). Euphytica 161: 241-257.

Malosetti, M., Voltas, J., Romagosa, I., Ullrich, S. E., and van Eeuwijk, F. A. 2004. Mixed models including environmental covariables for studying QTL by environment interaction. Euphytica 137:139-145.

Moyer, M. M., Londo, J. P., Gadoury, D. M., and Cadle-Davidson, L. 2015. Cold stress-induced disease resistance (SIDR): Indirect effects of low temperatures on host-pathogen interactions and disease progress in the grapevine powdery mildew pathosystem. Eur. J. Plant Pathol. 144:695-705.

Nass, H. A., Pedersen, W. L., Mackenzie, D. R., and Nelson, R. R. 1981. The residual effects of some "defeated" powdery mildew resistance genes in isolines of winter wheat. Phytopathology 71:1315-1318. 
Piepho, H. P. 2005. Statistical tests for QTL and QTL-by-environment effects in segregating populations derived from line crosses. Theor. Appl. Genet. 110:561-566.

R Core Team. 2014. R: A language and environment for statistical computing. Version 3.1.2. R Foundation for Statistical Computing, Vienna, Austria.

Ramming, D. W., Gabler, F., Smilanick, J., Cadle-Davidson, M., Barba, P., Mahanil, S., Frenkel, O., Milgroom, M. G., and Cadle-Davidson, L. 2012. Identification of race-specific resistance in North American Vitis species limiting Erysiphe necator hyphal growth. Phytopathology 102: 83-93.

Riaz, S., Tenscher, A. C., Ramming, D. W., and Walker, M. A. 2011. Using a limited mapping strategy to identify major QTLs for resistance to grapevine powdery mildew (Erysiphe necator) and their use in marker-assisted breeding. Theor. Appl. Genet. 122:1059-1073.

Sakia, R. M. 1992. The Box-Cox transformation technique-A review. Statistician 41:169-178.

Van Ooijen, J. 2011. Multipoint maximum likelihood mapping in a full-sib family of an outbreeding species. Genet. Res. 93:343-349.
Weßling, R., and Panstruga, R. 2012. Rapid quantification of plant-powdery mildew interactions by qPCR and conidiospore counts. Plant Methods 8:35.

Williams, P. H. 1989. Screening for resistance to diseases. Pages 335-352 in: The Use of Plant Genetic Resources. A. H. D. Brown, O. H. Frankel, D. R. Marshall, and J. T. Williams, eds. Cambridge University Press.

Yang, S., Fresnedo-Ramírez, J., Sun, Q., Manns, D. C., Sacks, G. L., Mansfield, A. K., Luby, J. J., Londo, J. P., Reisch, B. I., Cadle-Davidson, L., and Fennell, A. Y. 2016a. Next generation mapping of enological traits in an $F_{2}$ interspecific grapevine hybrid family. PLoS One 11:e0149560.

Yang, S., Fresnedo-Ramírez, J., Wang, M., Cote, L., Schweitzer, P., Barba, P., Takacs, E. M., Clark, M. D., Luby, J. J., Manns, D. C., Sacks, G. L., Mansfield, A. K., Londo, J. P., Fennell, A. Y., Gadoury, D. M., Reisch, B. I., Cadle-Davidson, L., and Sun, Q. 2016b. A next-generation marker genotyping platform (AmpSeq) in heterozygous crops: A case study for marker assisted selection in grapevine. Hortic. Res. 3:16002.

Yang, S., Zhang, X., Yue, J.-X., Tian, D., and Chen, J.-Q. 2008. Recent duplications dominate NBS-encoding gene expansion in two woody species. Mol. Genet. Genomics 280:187-198. 